\title{
Adhesion molecule expression on eosinophils in idiopathic eosinophilic pneumonia
}

\author{
M. Azuma, Y. Nakamura, T. Sano, Y. Okano, S. Sone
}

\begin{abstract}
Adhesion molecule expression on eosinophils in idiopathic eosinophilic pneumonia. M. Azuma, Y. Nakamura, T. Sano, Y. Okano, S. Sone. (CERS Journals Ltd 1996.

ABSTRACT: Idiopathic essinophilic pneumonia (IEP) is characterized by the accumulation of eosinophils in the alveolar spaces and the interstitium of the lung, frequently accompanied by peripheral eosinophilia.

To clarify the roles of adhesion molecules of eosinophils in the pathogenesis of eosinophilic pneumonia, we analysed their expression by eosinophil and T-lymphocyte populations in peripheral blood and bronchoalveolar lavage fluid (BALF) obtained from 11 patients with eosinophilic pneumonia, using flow cytometric methods.

Cell differentials in BALF showed increased numbers of eosinophils, the increase correlating with the number of activated T-lymphocytes in BALF. The expressions of CD11a (lymphocyte function-associated antigen-1 (LFA-1)), CD11b (Mac-1), CD18, CD49d (very late activation antigen-4 (VLA-4)), and CD62L (L-selectin) by eosinophils in BALF were all lower than those of eosinophils in peripheral blood. In contrast, CD54 (intercellular adhesion molecule-1 (ICAM-1)) was expressed by eosinophils in BALF, but not by those in peripheral blood.

These results indicate that intercellular adhesion molecule-1 expression by eosinophils in bronchoalveolar lavage fluid but not in peripheral blood may be induced by locally activated T-cells or macrophages and may be important in the pathogenesis of idiopathic eosinophilic pneumonia.
\end{abstract}

Eur Respir J., 1996, 9, 2494-2500.

Third Department of Internal Medicine, School of Medicine, Tokushima University, Japan.

Correspondence: Y. Nakamura Third Dept of Internal Medicine School of Medicine

Tokushima University

3-18-15 Kuramoto-cho

Tokushima 770

Japan

Keywords: Adhesion molecules bronchoalveolar lavage fluid eosinophils

idiopathic eosinophilic pneumonia intercellular adhesion molecule-1

Received: November 231995

Accepted after revision July 201996
Idiopathic eosinophilic pneumonia (IEP) is characterized by the accumulation of eosinophils in the alveolar spaces and the interstitium of the lung, frequently accompanied by peripheral eosinophilia [1]. However, the pathogenesis of IEP is still unclear. Recent studies have demonstrated that eosinophils are cytotoxic not only to parasites but also to the airway epithelium of asthmatics due to the release of toxic granule proteins, such as major basic protein (MBP), eosinophil cationic protein (ECP) and eosinophil peroxidase (EPO) [2-6]. In this context, IEP may be recognized as an eosinophil-induced lung injury, and modulation of eosinophil accumulation and activation may be important in the pathophysiology of IEP.

Recently, much attention has been focused on the importance of cell-cell interaction through adhesion molecules in the inflammatory process. Various adhesion molecules have been found to be involved in the migration of eosinophils to airway mucosa through vascular endothelial cells $[7,8]$. These adhesion molecules of eosinophils may be important in eosinophil influx into the lungs of IEP patients. On the other hand, T-lymphocyte-derived cytokines, including interleukin-5 (IL5), granulocyte/macrophage colony-stimulating factor (GM-CSF), and interleukin-3 (IL-3) are known to stimulate proliferation, activation, and survival of eosinophils $[9,10]$. Indeed, these cytokines are detectable at high concentrations in the airways of asthmatics and in the pleural cavity of patients with eosinophilic pleural effusions [11-15]. Little is known, however, about expression of adhesion molecules by eosinophils, or their abnormal regulation in IEP.

In this study, we analysed the expression of adhesion molecules by eosinophils and the relationship with cell populations in peripheral blood and bronchoalveolar lavage fluid (BALF) obtained from patients with IEP.

\section{Materials and methods}

\section{Subjects}

Studies were performed in 11 patients ( 8 males and 3 females) with IEP (aged (mean \pm SEM) $47 \pm 3$ yrs) (table 1 ) and in nine healthy subjects (aged $31 \pm 2$ yrs, all male). All IEP patients were diagnosed by transbronchial lung biopsy, in which they showed an increased number of eosinophils in alveolar spaces and septa, without granulomas or vasculitis. No pathogens were detected in biopsy specimens or BALF. The patients had no history of bronchial asthma or drug allergy. They had no appreciable occupational exposure to toxic fumes, dust or animals. The healthy subjects had no history of allergy, asthma or medication, and were used as controls in analysis of cell differentials in BALF. 
Table 1. - Characteristics of patients with idiopathic eosinophilic pneumonia

\begin{tabular}{|c|c|c|c|c|c|c|c|c|c|}
\hline \multirow[b]{2}{*}{$\begin{array}{l}\text { Case } \\
\text { No. }\end{array}$} & \multirow[b]{2}{*}{ Sex } & \multirow[b]{2}{*}{$\begin{array}{l}\text { Age } \\
\text { yrs }\end{array}$} & \multicolumn{3}{|c|}{ Peripheral blood } & \multicolumn{4}{|c|}{ Cell differentiation in BALF $\%$} \\
\hline & & & $\begin{array}{c}\text { WBC } \\
\times 10^{9} \cdot \mathrm{L}^{-1}\end{array}$ & $\begin{array}{c}\text { Eos } \\
\%\end{array}$ & $\begin{array}{c}\text { Eos } \\
\times 10^{9} \cdot \mathrm{L}^{-1}\end{array}$ & $\mathrm{AM}$ & Lym & $\mathrm{Neu}$ & Eos \\
\hline 1 & F & 32 & 10.9 & 16 & 1.7 & 81 & 6 & 0.6 & 12 \\
\hline 2 & $\mathrm{~F}$ & 39 & 4.2 & 7 & 0.3 & 65 & 1 & 0.8 & 33 \\
\hline 3 & $\mathrm{M}$ & 39 & 12.5 & 20 & 2.5 & 65 & 23 & 0.6 & 11 \\
\hline 4 & M & 42 & 15.0 & 38 & 5.7 & 49 & 12 & 3.9 & 36 \\
\hline 5 & $\mathrm{M}$ & 42 & 8.6 & 26 & 2.2 & 40 & 4 & 1.8 & 54 \\
\hline 6 & $\mathrm{M}$ & 45 & 18.0 & 4 & 0.7 & 53 & 14 & 17.8 & 15 \\
\hline 7 & $\mathrm{~F}$ & 46 & 8.3 & 45 & 3.7 & 33 & 10 & 4.8 & 52 \\
\hline 8 & $\mathrm{M}$ & 50 & 6.0 & 5 & 0.3 & 46 & 36 & 1.4 & 17 \\
\hline 9 & $\mathrm{M}$ & 50 & 9.1 & 8 & 0.7 & 17 & 7 & 0.2 & 76 \\
\hline 10 & $\mathrm{M}$ & 67 & 4.1 & 10 & 0.4 & 81 & 2 & 0.2 & 16 \\
\hline 11 & M & 69 & 4.1 & 0.5 & 0.02 & 61 & 14 & 4.9 & 20 \\
\hline Mean & & 47 & 9.2 & 16 & 1.7 & 54 & 12 & 3.4 & 31 \\
\hline SEM & & 3 & 1.4 & 4 & 0.5 & 6 & 3 & 1.5 & 6 \\
\hline
\end{tabular}

M: male; F: female; Eos: eosinophils; WBC: white blood cells; AM: alveolar macrophages; Lym: lymphocytes; Neu: neutrophils. BALF: bronchoalveolar lavage fluid.

\section{Bronchoalveolar Lavage}

Bronchoalveolar lavage (BAL) was performed in subjects after obtaining their informed consent [ 16]. The oral cavity and the upper airway were anaesthetized with lidocaine spray, and the tip of a fibreoptic bronchoscope (Model BF-1T20; Olympus Co., Tokyo, Japan) was wedged into one bronchus of the middle lobe or lingula. The alveolar space was lavaged with $50 \mathrm{~mL}$ of sterile, isotonic saline $(0.9 \% \mathrm{NaCl})$ warmed to $37^{\circ} \mathrm{C}$, and the fluid was gently aspirated with a $50 \mathrm{~mL}$ syringe. This process was repeated three times. The BALF was filtered through a single layer of gauze and then centrifuged at $250 \times \mathrm{g}$ for $10 \mathrm{~min}$. The resulting cell pellet was suspended in RPMI 1640 medium containing 10\% heat-inactivated foetal calf serum (FCS), and part of the cell suspension was used for analysis of lymphocyte subpopulations. The total number of cells was determined with a haemocytometer, and differential cell counts were made on preparations obtained by cytocentrifugation using Cytospin 2 (Shandon Southern Products, Manchester, UK) and staining with Diff-Quik stain (Baxter Dade AG, Duedingen, Switzerland).

BAL was routinely performed in the lingula or middle lobe, not other sites, for two reasons. One was adjustment of the recovery rates of BAL fluid in patients and healthy subjects. The other was evidence of the presence of eosinophilia even in a lobe without any abnormal shadow on chest radiograph examination of IEP patients, as reported previously [17]. The first aliquot of BALF was not separated from the other for two reasons: 1) adjustment of the technical conditions in patients and healthy subjects; 2) no obvious signs of bronchial inflammation were found on bronchoscopy of patients in this study, indicating that mixture of lavage from bronchi (the first aliquot) with second and third lavages did not affect the analysis of BALF.

\section{Isolation of eosinophils from peripheral blood and BALF}

Heparinized peripheral blood was taken from patients with IEP before bronchoscopic examination and corticosteroid therapy, after obtaining their informed consent.
Granulocytes were separated by the dextran sedimentation method, and centrifuged on lymphocyte separation medium with a density of $1.077-1.080 \mathrm{~g} \cdot \mathrm{mL}^{-1}$ (Organon Teknica Corp., Durham, NC, USA) to remove mononuclear cells [18]. Contaminating red blood cells were eliminated by hypotonic lysis. Eosinophils were then isolated by the negative selection method described previously [19]. Briefly, the granulocyte pellet was incubated with mouse monoclonal anti-human CD16 antibody for 30 $\min$ at $4^{\circ} \mathrm{C}$, and then with anti-mouse immunoglobulin $\mathrm{G}_{1}\left(\mathrm{IgG}_{1}\right)$ antibody bound to micromagnetic beads (Dynabeads M-450, Dynal Inc., NY, USA). The beads with bound neutrophils were then removed from the granulocyte suspension by placing them in a magnetic holder. These procedures resulted in consistent purification of eosinophils (99\%, as judged by May-GrunwaldGiemsa staining), and more than $98 \%$ of the cells were viable, as judged by the trypan blue exclusion test.

Eosinophils were obtained from BAL samples using the same procedure as used for peripheral blood. The purity of the eosinophils obtained was $96 \%$, as judged by May-Grunwald-Giemsa staining, and more than $93 \%$ of the cells were viable, as judged by the trypan blue exclusion test. The recovery rates of eosinophils by this separation method were $55 \pm 2 \%$ and $49 \pm 3 \%$ from peripheral blood and BAL samples, respectively.

\section{Flow-cytometric analysis of lymphocyte subpopulations}

Part of the BALF cell sample was suspended in phosphate-buffered saline (PBS) containing 1\% FCS, and part was incubated with fluorescein isothiocyanate (FITC) and/or phycoerythrin (PE)-conjugated antibody (table 2 ), at the optimal concentrations prescribed by the manufacturer, for $30 \mathrm{~min}$ at $4^{\circ} \mathrm{C}$. Contaminating red blood cells were eliminated by hypotonic lysis. Single or twocolour analysis with a FACScan (Becton-Dickinson) was used (at least 5,000 events were assumed for each sample). A cell gate containing lymphocytes was established on the basis of forward and side light scattering. Lymphocyte gates were validated by employing CD45FITC-conjugated and CD14-PE-conjugated monoclonal 
Table 2. - CD, characteristics, specificity and source of monoclonal antibodies employed

\begin{tabular}{|c|c|c|}
\hline $\mathrm{CD}$ & Antibody & Specificity \\
\hline CD3 & Anti-Leu 4* & Mature T-lymphocytes \\
\hline CD4 & Anti-Leu $3 *$ & Helper-inducer T-lymphocytes \\
\hline CD8 & Anti-Leu $2 *$ & $\begin{array}{l}\text { Suppressor-cytotoxic } \\
\text { T-lymphocytes }\end{array}$ \\
\hline CD9 & Anti-M-L13 ${ }^{\dagger}$ & Eosinophils \\
\hline CD11a & Anti-G25.2* & $\beta_{2}$-integrin $\alpha$-chain \\
\hline CD11b & Anti-D12* & $\beta_{2}$-integrin $\alpha$-chain \\
\hline CD14 & Anti-Leu M3* & Monocytes \\
\hline CD16 & Anti-3G8§ & IgG Fc receptor \\
\hline CD18 & Anti-L130* & $\beta_{2}$-integrin $\beta$-chain \\
\hline CD20 & Anti-Leu $16^{*}$ & Pan B-lymphocytes \\
\hline CD25 & Anti-IL-2R* & p55 IL-2 receptor \\
\hline CD44 & Anti-J-173\# & Hyaluronate receptor \\
\hline CD45 & Anti-Leu M1* & Pan-leucocyte \\
\hline CD49d & Anti-HP2/1 \# & $\beta_{1}$-integrin $\alpha$-chain \\
\hline CD54 & Anti-LB2* & ICAM-1 \\
\hline CD58 & Anti-AICD58\# & LFA-3 \\
\hline \multirow[t]{2}{*}{ CD62L } & Anti-SK11* & L-selectin \\
\hline & Anti-HLA-DR ${ }^{\dagger}$ & MHC class II related antigen \\
\hline
\end{tabular}

*: Becton-Dickinson (Mountain View, CA, USA); \#: Cosmo Bio Co. Ltd (Tokyo, Japan); Pharmingen (San Diego, CA, USA); §: Medarex Inc. (West Lebanon, NH, USA); ICAM-1: intercellular adhesion molecule-1; LFA-3: lymphocyte function associated antigen-3; HLA-DR: human lymphocyte antigen DR; MHC: major histocompatibility complex; IgG: immunoglobulin G; IL-2: interleukin-2; IL-2R: interleukin2 receptor.

antibodies. The lymphocyte population was defined as CD45+/CD14-. More than $96 \%$ of all lymphocytes in each sample were contained within the boundaries of the lymphocyte light-scatter gate.

Flow-cytometric analysis of eosinophil surface molecules

For immunofluorescence staining of eosinophils obtained from peripheral blood or BALF, $1 \times 10^{6}$ cells in $100 \mu \mathrm{L}$ of PBS containing $1 \%$ FCS were incubated with the isotype-matched control antibody (Ancell, MN, USA) or primary antibody for each surface molecule (table 2), at the optimal concentrations prescribed by the manufacturer, for $30 \mathrm{~min}$ at $4^{\circ} \mathrm{C}$. The cells were then washed twice in PBS with $1 \%$ FCS, and incubated with the second antibody conjugated with FITC (Immunotech Inc., ME, USA) at optimal concentrations, for $30 \mathrm{~min}$ at $4^{\circ} \mathrm{C}$.

Flow-cytometric analysis was performed with a FACScan (Becton Dickinson). Eosinophil gates were obtained by linear forward angle light scatter: the eosinophil gates were validated using CD9 (eosinophils) and CD16 (neutrophils). The eosinophil population was defined as CD9+/CD16-. Single colour analysis with FACScan (Becton Dickinson) was used. The number of immunofluorescence-positive cells per 10,000 cells analysed was determined. Fluorescence limits were set so that only $2 \%$ of control-stained cells fell within the positive domain. Results on surface molecule expression are presented as percentages of cells exhibiting greater fluorescence than that of the isotype control.

\section{Statistical analysis}

Results are expressed as means \pm SEM. The significance of the difference between data was evaluated by Student's t-test. Pearson's linear regression was applied to examine the correlation between various parameters. A p-value less than 0.05 was considered as statistically significant.

\section{Results}

\section{Cell populations in peripheral blood and BALF}

Cell populations in the peripheral blood and BALF are shown in tables 1 and 3 . The mean percentage of eosinophils in BALF of patients with IEP was $31 \pm 6 \%$ $(11-76 \%)$ and there was no significant correlation between the percentage of eosinophils in BALF and that in peripheral blood. The mean $\mathrm{CD} 4 / \mathrm{CD} 8$ ratio was $1.5 \pm 0.4$. The mean number of eosinophils in BALF of patients with IEP $\left(19.0 \pm 6.3 \times 10^{6}\right.$ cells; $\left.n=11\right)$ was significantly greater than that in BALF of healthy subjects $\left(0.01 \pm 0.01 \times 10^{6}\right.$ cells; $n=9)(p<0.04)$. The mean numbers of macrophages and lymphocytes in BALF of patients with IEP $\left(27.0 \pm 5.1 \times 10^{6}\right.$ cells and $8.6 \pm 3.3 \times 10^{6}$ cells respectively; $\mathrm{n}=11$ ) were significantly greater than those in BALF of healthy subjects $\left(9.9 \pm 1.4 \times 10^{6}(\mathrm{p}<0.03)\right.$ and $0.8 \pm 0.2 \times 10^{6}$ cells $(\mathrm{p}<0.04)$, respectively $\mathrm{n}=9)$. The number of lymphocytes in BALF of healthy subjects was so small that analysis of lymphocyte subpopulations was not possible. In this study, there was no significant difference in the cell populations or lymphocyte subpopulations in the BALF of smokers $(n=6)$ and nonsmokers $(n=S)$ among IEP patients (data not shown).

Correlation between eosinophil number and lymphocyte subpopulation in BALF of IEP patients

Since lymphocytes are among the most important cells involved in the regulation of eosinophil behaviour, we analysed the correlation between the eosinophil number and lymphocyte subpopulations in BALF of IEP patients. There was no correlation between the absolute

Table 3. - Lymphocyte subpopulations in BAL fluid from IEP patients

\begin{tabular}{|c|c|c|c|c|c|c|}
\hline \multirow{3}{*}{$\begin{array}{l}\text { Case } \\
\text { No. }\end{array}$} & \multicolumn{6}{|c|}{ Lymphocyte subpopulations } \\
\hline & $\mathrm{CD} 3$ & CD4 & CD8 & $\mathrm{CD} 20$ & CD3(+)CD25(+) & $\mathrm{CD} 4 / \mathrm{CD} 8$ \\
\hline & $\%$ & $\%$ & & & & ratio \\
\hline 1 & 90 & 55 & 33 & 2.6 & 7 & 1.7 \\
\hline 2 & 96 & 35 & 52 & 4.2 & 5 & 0.7 \\
\hline 3 & 99 & 6 & 93 & 1.0 & 4 & 0.1 \\
\hline 4 & 82 & 71 & 16 & 3.5 & 15 & 4.5 \\
\hline 5 & 82 & 56 & 24 & 4.3 & 20 & 2.3 \\
\hline 6 & 94 & 32 & 61 & 1.8 & 4 & 0.5 \\
\hline 7 & 90 & 23 & 66 & 1.1 & 17 & 0.4 \\
\hline 8 & 79 & 13 & 66 & 1.5 & ND & 0.2 \\
\hline 9 & 77 & 56 & 18 & 6.7 & 24 & 3.1 \\
\hline 10 & 67 & 44 & 16 & 5.3 & 9 & 2.8 \\
\hline 11 & 85 & 29 & 41 & 1.1 & 10 & 0.7 \\
\hline Mean & 86 & 38 & 44 & 3.0 & 12 & 1.5 \\
\hline SEM & 3 & 6 & 8 & 0.6 & 2 & 0.4 \\
\hline
\end{tabular}

ND: not determined; BAL: bronchoalveolar lavage; IEP: idiopathic eosinophilic pneumonia. 
a)

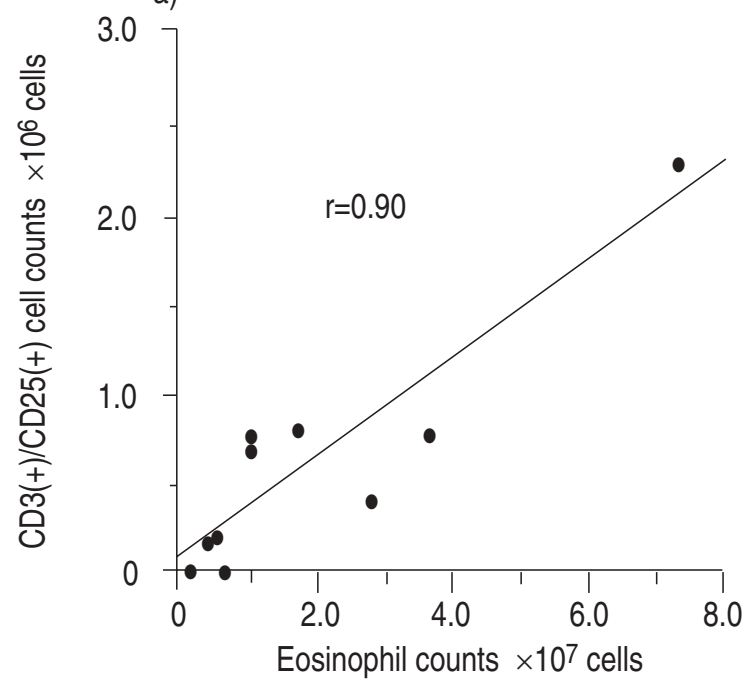

b)

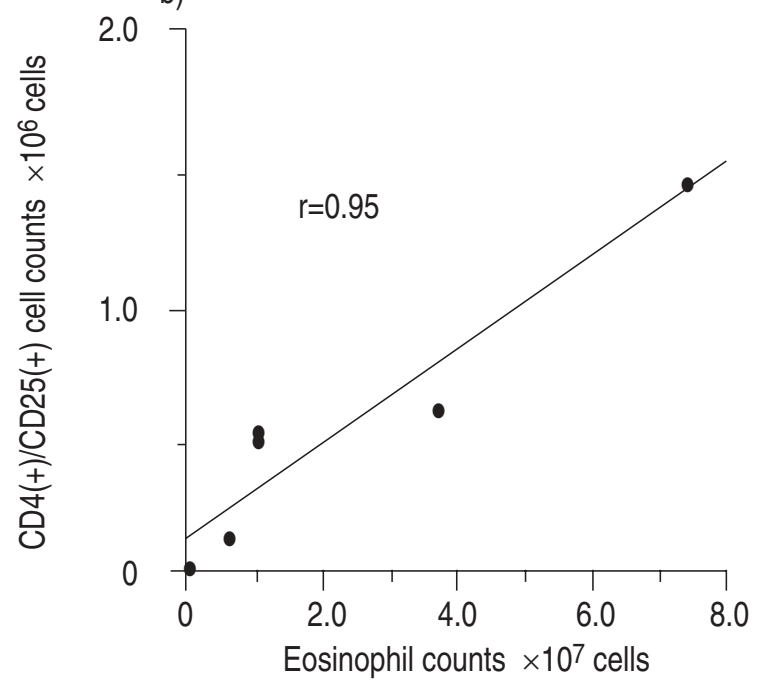

Fig. 1. - Correlations between a) the eosinophil number and number of activated T-lymphocytes $(\mathrm{CD} 3+/ \mathrm{CD} 25+\mathrm{cells})(\mathrm{r}=0.90$; $\mathrm{p}<0.0005$; $\mathrm{n}=10)$; and $b)$ the eosinophil number and number of activated helper T-lymphocytes (CD4+/CD25+ cells) $(r=0.95 ; p<0.004 ; n=6)$ in bronchoalveolar lavage fluid from patients with eosinophilic pneumoma.

a)

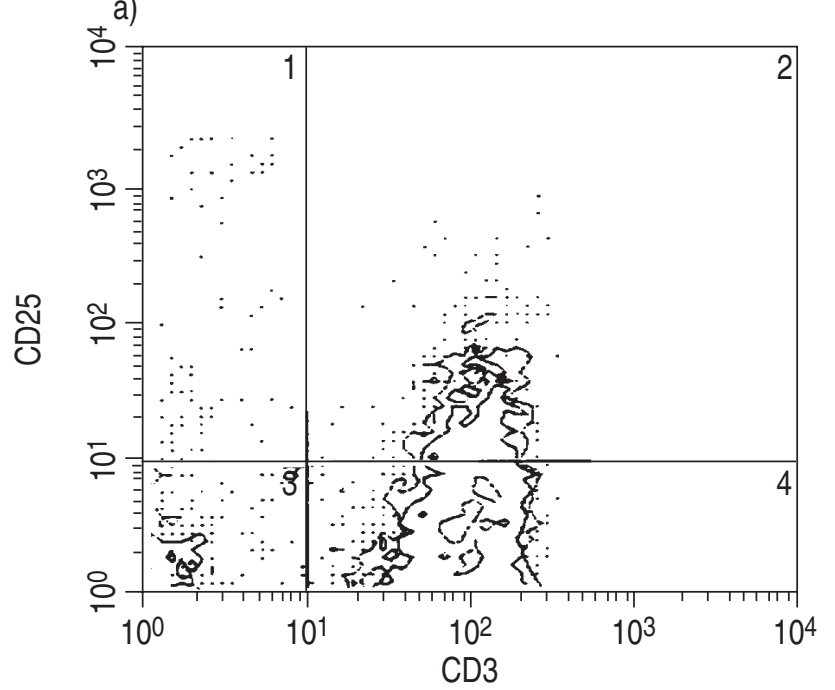

b)

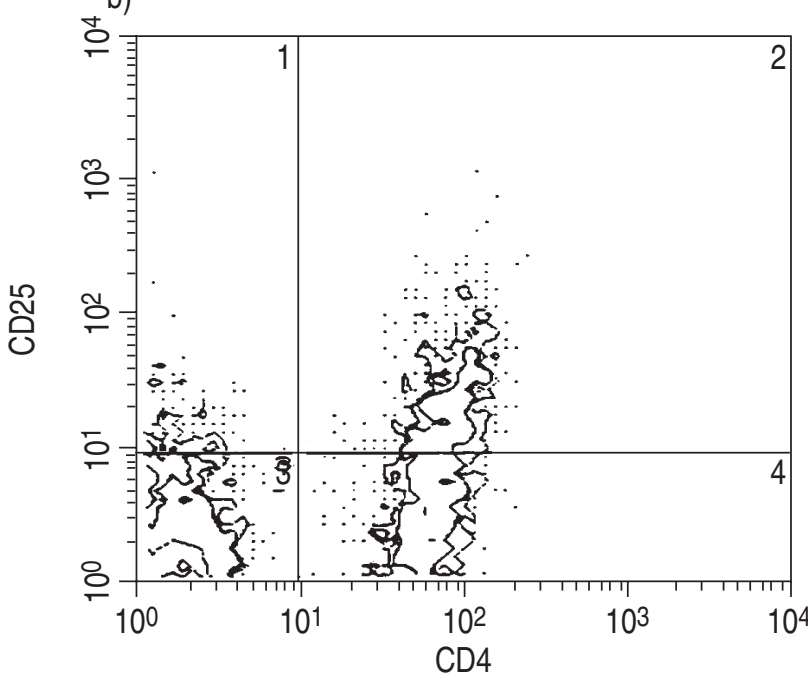

Fig. 2. - Representative dot-plot of a) CD3+/CD25+; and b) CD4+/CD25+ T-lymphocytes in BALF. The expressions of each surface marker were determined by FACS analysis, as described in Materials and methods. The numbers in the histogram mean: CD3-/CD25+ or CD4-/CD25+ (left upper section: 1); CD3+/CD25+ or CD4+/CD25+ (right upper section: 2); CD3-/CD25- or CD4-/CD25- (left lower section: 3); and CD3+/CD25or CD4+/CD25- (right lower section: 4) cells in BALF. BALF: bronchoalveolar lavage fluid; FACS: fluorescence-activated cell sorter.

number of eosinophils and lymphocyte subpopulations, including CD3 ( $\mathrm{r}=0.31), \mathrm{CD} 4$ ( $\mathrm{r}=0.40), \mathrm{CD} 8$ ( $\mathrm{r}=0.21)$, and CD20 ( $r=0.54)$. Significant correlations were found between the eosinophil number in BALF of IEP patients and the numbers of activated T-lymphocytes (CD3/CD25 co-expressing cells $)(\mathrm{r}=0.90, \mathrm{p}<0.0005 ; \mathrm{n}=10)$ and activated helper T-lymphocytes (CD4/CD25 co-expressing cells) $(\mathrm{r}=0.95, \mathrm{p}<0.04$; $\mathrm{n}=6)$ (figs 1 and 2 ).

Adhesion molecule expression by eosinophils in BALF and peripheral blood

The expressions of various adhesion molecules by eosinophils in BALF from IEP patients were compared with those in the peripheral blood from the same patients. Evaluations of the expression rates in peripheral blood and BALF showed significantly lower expressions by eosinophils in BALF of: CD11a (lymphocyte function-associated antigen-1 (LFA-1)); CD11b (Mac-1); CD18; CD49d (very late activation antigen-4 (VLA-4)); and CD62L (L-selectin) (fig. 3 and table 4). In contrast, eosinophils in BALF showed a significantly higher expression of CD54 (intercellular adhesion molecule-1 (ICAM-1)). The expressions of other molecules, by eosinophils in BALF and in peripheral blood were similar: i.e. CD44, CD58 (late function antigen-3 (LFA-3)), and human leucocyte antigen-DR (HLA-DR).

\section{Discussion}

The present study has demonstrated that eosinophils in BALF of IEP patients show lower expressions of CD11a, CD11b, CD18, CD49d and CD62L, but higher expression of ICAM-1 than those in peripheral blood, 
PB
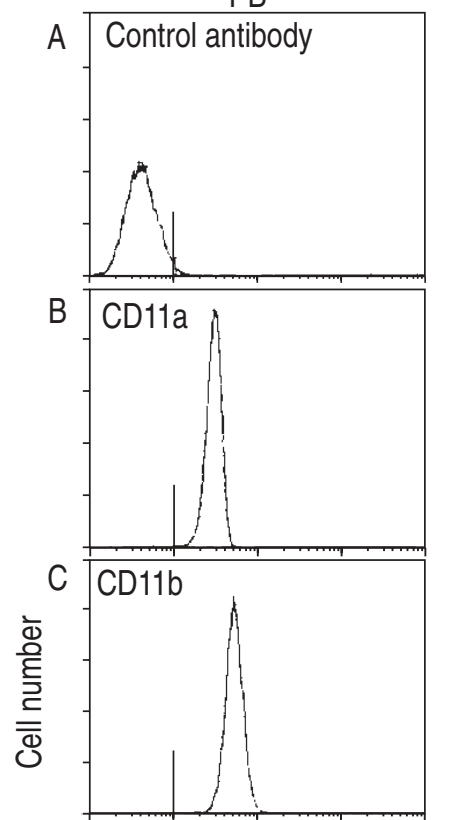

D

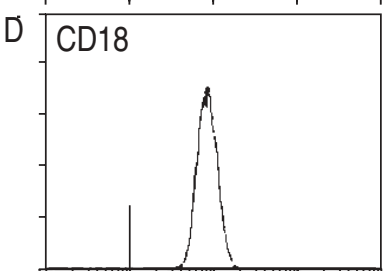

E

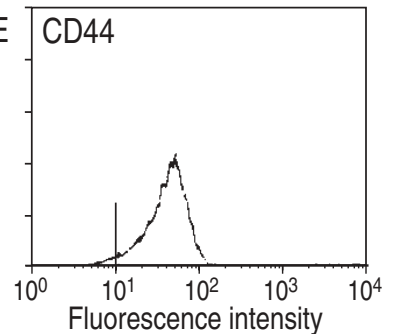

BALF
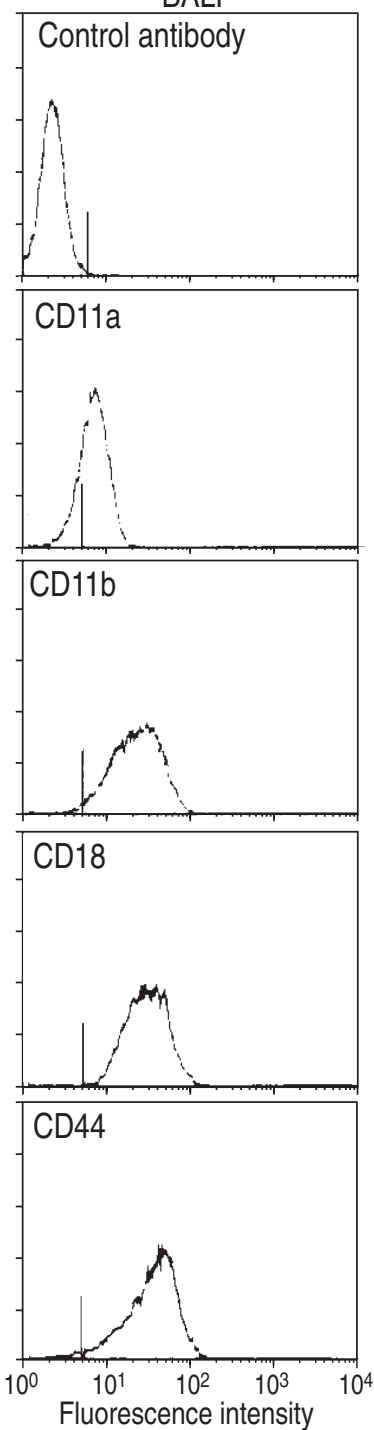
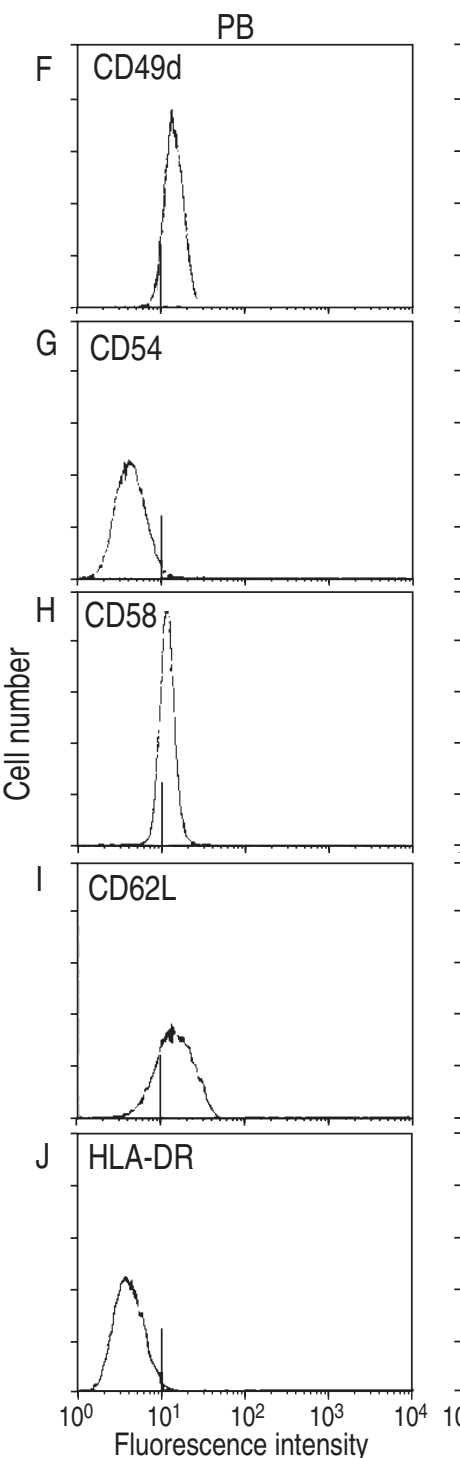
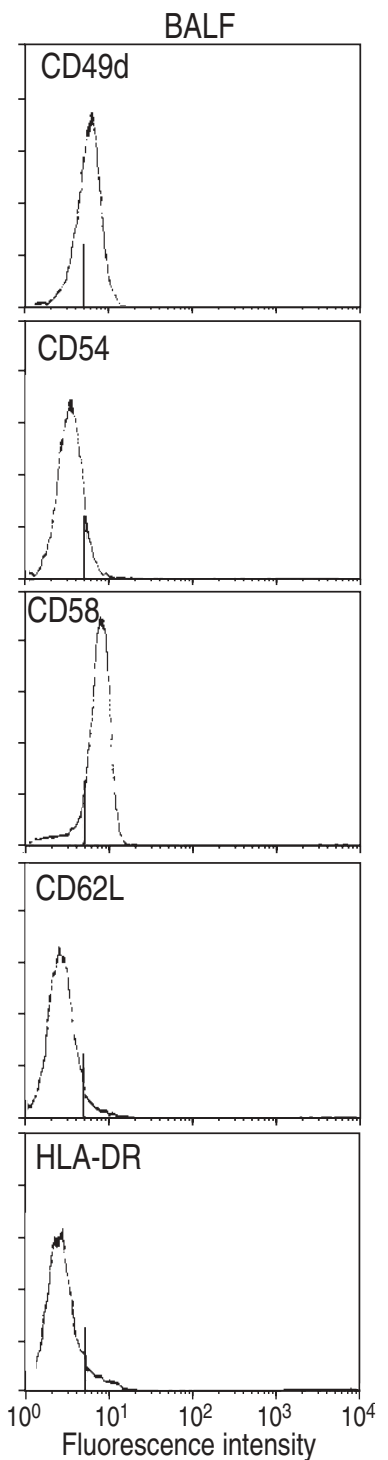

Fig. 3. - Representative histograms of spontaneous expression of adhesion molecules on eosinophils separated from peripheral blood (PB) (first and third column) or bronchoalveolar lavage fluid (BALF) (second and fourth column) of IEP patients. The expression of each adhesion molecule was determined by FACS analysis, as described in Materials and methods. Data are shown as a histograms of cell numbers versus log fluorescence intensities. Histograms are for one of three separate experiments. Vertical bars in histograms show cut-offs for control antibody staining. Alphabetic letters indicate staining was performed with the following antiadhesion molecule antibodies: A: control antibody; B: CD11a; C: CD11b; D: CD18; E: CD44; F: CD49d; G: CD54; H: CD58; I: CD62L; and J: HLA-DR. IEP: idiopathic eosinophilic pneumonia; FACS: fluorescence-activated cell sorter; HLA-DR: human leucocyte antigen-DR.

Table 4. - Expression pf surface molecules on eosinophils in PB and BALF of IEP patients

\begin{tabular}{lll}
\hline & PB & \multicolumn{1}{c}{ BAL } \\
\hline CD11a & $97 \pm 0.1$ & $72 \pm 6^{* *}$ \\
CD11b & $98 \pm 0.1$ & $92 \pm 1.2^{* *}$ \\
CD18 & $97 \pm 0.3$ & $94 \pm 1.4^{*}$ \\
CD44 & $95 \pm 2$ & $95 \pm 0.3$ \\
CD49d & $94 \pm 1.0$ & $49 \pm 12^{* *}$ \\
CD54 & $0.5 \pm 0.3$ & $34 \pm 12^{*}$ \\
CD58 & $88 \pm 5$ & $89 \pm 6$ \\
CD62L & $82 \pm 7$ & $10 \pm 5^{* *}$ \\
HLA-DR & $2.6 \pm 2.6$ & $39 \pm 20$ \\
\hline
\end{tabular}

Values are expressed as mean \pm SEM. PB: peripheral blood; BALF: bronchoalveolar lavage fluid; IEP: idiopathic eosinophilic pneumonia; HLA-DR: human leucocyte antigenDR. *: $\mathrm{p}<0.05 ; * *: \mathrm{p}<0.01$, compared to peripheral blood. and that there is a close correlation between the eosinophil number and the number of activated T-lymphocytes in the BALF.

Much attention has been paid to the roles of eosinophils and T-lymphocytes in the induction of inflammatory reactions in allergic diseases, such as atopic rhinitis and bronchial asthma [2-4]. In a model of eosinophil infiltration into the trachea of ovalbumin-sensitized mice, eosinophil infiltration was found to be mediated by CD4+ T-lymphocytes and IL-5. Little is known, however, about the role of T-lymphocytes in the pathogenesis of IEP. This study has clearly demonstrated that T-lymphocytes in BALF of IEP patients are in an activated state, as characterized by an increased number of CD25 (interleukin2 receptor (IL-2R))+ cells. Moreover, the proportion and absolute number of CD25+/CD4+ T-lymphocytes in 
BALF in IEP were found to correlate significantly with the eosinophil count in BALF, indicating an important role of activated CD4+ T-lymphocytes in eosinophilia associated with IEP (fig. 1). In other studies, the percentage of CD25+/CD4+ T-lymphocytes in BALF was found to be significantly higher in IEP patients than in healthy subjects $[1,20]$. The percentages of other lymphocyte subsets, such as CD3, CD4 and CD8, and the CD4/CD8 ratio, however, were similar in BALF of IEP patients and healthy subjects. These results are consistent with those of the present study.

The present findings, as well as those of previous reports [20-22], demonstrate that the BALF of patients with IEP has a high percentage of eosinophils. Adhesion molecules are expected to be involved in recruitment and activation of eosinophils in the pathogenesis of IEP, since several in vitro studies have demonstrated the importance of eosinophil surface molecules in the interaction of eosinophils with other cells [23, 24].

Modulation of adhesion molecules of eosinophils by cytokines affects their functions in the development and maintenance of allergic reactions [25]. For example, the administration of anti-ICAM-1 antibody was found to reduce eosinophil infiltration and attenuate airway hyperresponsiveness in a primate model of chronic airway inflammation [26]. The CD11/CD18 $\beta_{2}$-integrin adhesion complex, which is a ligand for ICAM-1, is known to be important in the process of eosinophil transendothelial migration [7]. However, little is known about the changes in expression of adhesion molecules on eosinophils in the lung of IEP patients. In the present study, it was found that eosinophils in BALF of IEP patients showed lower expression of the adhesion molecules CD11a, CD11b, CD18, CD49d and CD62L than eosinophils in their peripheral blood. The lower expressions of these adhesion molecules might be due to their consumption or internalization during eosinophil migration to inflammatory sites in the lung. This possibility is supported by a previous finding that the expressions of CD11a and CD18 by eosinophils were decreased after their migration across interleukin-1 (IL-1)-activated human vascular endothelial cells [27]. It is also possible that various cytokines may affect expression of adhesion molecules on eosinophils infiltrating inflammatory sites of the lung, because type $2 \mathrm{~T}$-helper (Th2)like cytokines (IL-5 and GM-CSF) were found to decrease CD49d expression on eosinophils [28].

In contrast, the expressions of ICAM-1 and HLA-DR on eosinophils in BALF of patients with IEP were higher than those on eosinophils in blood. This observation suggests that eosinophils in BALF of IEP patients are in the activated state, because activated eosinophils are known to show high expressions of ICAM-1 and HLADR [29-31]. This upregulation of the expression of ICAM-1 and HLA-DR by eosinophils in BALF may be important in promoting their interaction with T-lymphocytes in the lung.

Interestingly, the number of alveolar macrophages recovered from IEP patients was significantly higher than that recovered from healthy donors. Alveolar macrophages are known to produce and secrete various cytokines, such as TNF- $\alpha$, IL-1, interleukin-6 (IL-6) and GM-CSF [32-34]. Alveolar macrophages collected from the lungs of asthmatic patients after antigen challenge were found to produce high levels of IL-6 and TNF- $\alpha$ [35]. Since alveolar macrophages can be triggered by immunoglobulin $\mathrm{E}$ ( $\mathrm{IgE}$ ) to produce these cytokines [36], expression of ICAM-1 on eosinophils in BALF, but not in the blood, of IEP patients might be induced by macrophages in the lung through various cytokines.

Cigarette smoking is known to affect the absolute cell number and cell differential in BALF [37]. Unexpectedly, we found no significant difference in either the absolute cell number or cell differential between smokers and nonsmokers in IEP patients. This may be due to the increase of eosinophils, which might interfere with cell populations and lymphocyte subpopulations in the BALF, although there is no evidence for this.

The present study extends our understanding of the pathogenesis of eosinophilic pneumonia. Measurements of adhesion molecule expression of infiltrated cells, Tlymphocyte activation and cytokines in bronchoalveolar lavage fluid may be helpful in evaluating disease activity in idiopathic eosinophilic pneumonia, and in therapeutic monitoring of individual idiopathic eosinophilic pneumonia patients.

Acknowledgement: The authors would like to thanks $\mathrm{H}$. Bando (Tokushima Prefectual Central Hospital) for providing the samples used in this study.

\section{References}

1. Albera C, Ghio P, Solidoro P, et al. Activated and memory alveolar T-lymphocytes in idiopathic eosinophilic pneumonia. Eur Respir J 1995; 8: 1281-1285.

2. Bousquet J, Chanez P, Lacoste JY, et al. Eosinophilic inflammation in asthma. N Engl J Med 1990; 323: 1033-1039.

3. Gleich GJ. The eosinophil and bronchial asthma: current understanding. J Allergy Clin Immunol 1990; 85: 422-436.

4. Kay AB. Asthma and inflammation. J Allergy Clin Immunol 1991; 87: 893-910.

5. Motojima S, Frigas E, Loegering DA, Gleich GJ. Toxicity of eosinophil cationic proteins for guinea-pig tracheal epithelium in vitro. Am Rev Respir Dis 1989; 139: 801-805.

6. Venge P, Dahl R, Fredens K, Peterson CGB. Epithelial injury by human eosinophils. Am Rev Respir Dis 1988; 138: S54-S57.

7. Ebisawa M, Bochner BS, Georas SN, Schleimer RP. Eosinophil transendothelial migration induced by cytokines. I. Role of endothelial and eosinophil adhesion molecules in IL-1 beta-induced transendothelial migration. J Immunol 1992; 149: 4021-4028.

8. Murray B, Weller PF. Mechanisms of eosinophil recruitment. Am J Respir Cell Mol Biol 1993; 8: 349-355.

9. Clutterbuck EJ, Hirst EMA, Sanderson CJ. Human interleukin-5 (IL-5) regulates the production of eosinophils in human bone marrow cultures: comparison and interactions with IL-1, IL-3, IL-6 and GM-CSF. Blood 1989; 73: $1504-1512$.

10. Lopez AF, Williamson J, Gamble JR, et al. Recombinant human granulocyte macrophage colony-stimulating factor stimulates in vitro mature human neutrophil and eosinophil function, surface receptor expression, and survival. J Clin Invest 1986; 78: 1220-1228.

11. Nakamura Y, Ozaki T, Yanagawa H, Yasuoka S, Ogura T. Eosinophil colony-stimulating factor induced by 
administration of interleukin-2 into the pleural cavity of patients with malignant pleurisy. Am J Respir Cell Mol Biol 1990; 3: 291-300.

12. Broide DH, Lotz M, Cuomo AJ, Coburn DA, Federman EC, Wasserman SI. Cytokines in symptomatic asthmatic airways. J Allergy Clin Immunol 1992; 89: 958-967.

13. Ohnishi T, Kita H, Weiler D, et al. IL-5 is the predominant eosinophil-active cytokine in the antigeninduced pulmonary late-phase reaction. Am Rev Respir Dis 1993; 147: 901-907.

14. Kamei T, Ozaki T, Kawaji K, et al. Production of interleukin-5 and granulocyte/macrophage colony-stimulating factor by T-cells of patients with bronchial asthma in response to Dermatophagoides farinae and its relation to eosinophil colony-stimulating factor. Am J Respir Cell Mol Biol 1993; 9: 378-385.

15. Nakamura Y, Ozaki T, Kamei T, et al. Factors that stimulate the proliferation and survival of eosinophils in eosinophilic pleural effusion: relationship to granulocyte/macrophage colony-stimulating factor, interleukin5 and interleukin-3. Am J Respir Cell Mol Biol 1993; 8: 605-611.

16. Sone S, Orino E, Mizuno K, et al. Production of IL-1 and its receptor antagonist is regulated differently by IFN- $\gamma$ and IL-4 in human monocytes and alveolar macrophages. Eur Respir J 1994; 7: 657-663.

17. Dejaegher P, Derveaux L, Dubois P, et al. Eosinophilic pneumonia without radiographic pulmonary infiltrates. Chest 1983; 84: 637-638.

18. Nakamura Y, Ozaki T, Kamei T, et al. Increased granulocyte/macrophage colony-stimulating factor production by mononuclear cells from peripheral blood of patients with bronchial asthma. Am Rev Respir Dis 1993; 147: 87-91.

19. Hansel TT, Pound JD, Pilling DP, et al. Purification of human blood eosinophils by negative selection using immunomagnetic beads. J Immunol Methods 1989; 122: 97-103.

20. Walker C, Bauer W, Braun RK, et al. Activated T-cells and cytokines in bronchoalveolar lavages from patients with various lung diseases associated with eosinophilia. Am J Respir Crit Care Med 1994; 150: 1038-1048.

21. Ogushi F, Ozaki T, Kawano T, Yasuoka S. $\mathrm{PGE}_{2}$ and $\mathrm{PGF}_{2 \alpha}$ content in bronchoalveolar lavage fluid obtained from patients with eosinophilic pneumonia. Chest 1987; 91: 204-206.

22. Hayakawa H, Sato A, Toyoshima M, Imokawa S, Taniguchi M. A clinical study of idiopathic eosinophilic pneumonia. Chest 1994; 105: 1462-1466.

23. Hansel TT, De Vries IJM, Carballido JM, et al. Induction and function of eosinophil intercellular adhesion molecule-1 and HLA-DR. J Immunol 1992; 149: 2130-2136.

24. Weller PF, Rand TH, Goelz SE, Chi-Rosso C, Lobb RR. Human eosinophil adherence to vascular endothelium mediated by binding to vasucular cell adhesion molecule-1 and endothelial leukocyte adhesion molecule-1. Proc Natl Acad Sci USA 1991; 88: 7430-7433.

25. Walsh GM, Hartnell A, Wardlaw AJ, Kurihara K, Sanderson CJ, Kay AB. IL-5 enhances the in vitro adhesion of human eosinophils, but not neutrophils, in a leukocyte integrin (CD11/18)-dependent manner. Immunology 1990; 71: 258-265.

26. Wegner CD, Gundel RH, Reilly N, Haynes N, Letts G, Rothlein G. Intercellular adhesion molecule-1 (ICAM-1) in the pathogenesis of asthma. Science 1990; 247: 456459.

27. Walker C, Rihs S, Braun RK, Betz S, Bruijnzeel PLB. Increased expression of $\mathrm{CD} 11 \mathrm{~b}$ and functional changes in eosinophils after migration across endothelial cell monolayers. J Immunol 1993; 150: 4061-4071.

28. Fukuda T, Numao T, Fukushima Y, Sagara H, Motojima S, Makino S. Eosinophilopoietic cytokines may be involved in decreased VLA-4 expression on BAL eosinophils (Abstract). J Allergy Clin Immunol 1994; 93: 269.

29. Czech W, Krutmann J, Budnik A, Schopf E, Kapp A. Induction of intercellular adhesion molecule-1 (ICAM1) expression in normal human eosinophils by inflammatory cytokines. J Invest Dermatol 1993; 100: 417-423.

30. Beninati W, Derdak S, Dixon PF, et al. Pulmonary eosinophils express HLA-DR in chronic eosinophilic pneumonia. J Allergy Clin Immunol 1993; 92: 442-449.

31. Okubo Y, Hossain M, Kai R, et al. Adhesion molecules on eosinophils in acute eosinophilic pneumonia. Am J Respir Crit Care Med 1995; 151: 1259-1262.

32. Elias JA, Schreiber AD, Gustilo K, et al. Differential interleukin-1 elaboration by unfractionated and density fractionated human alveolar macrophages and blood monocytes: relationship to cell maturity. J Immunol 1985; 135: 3198-3204.

33. Martinet Y, Yamauchi K, Crystal RG. Differential expression of the tumor necrosis factor/cachectin gene by blood and lung mononuclear phagocytes. Am Rev Respir Dis 1988; 1338: 659-665.

34. Kotloff RM, Little J, Elias JA. Human alveolar macrophage and blood monocyte interleukin-6 production. Am J Respir Cell Mol Biol 1990; 3: 497-505.

35. Lassalle P, Gosset P, Delneste Y, et al. Modulation of adhesion molecule expression on endothelial cells during the late asthmatic reaction: role of macrophagederived tumor necrosis factor- $\alpha$. Clin Exp Immunol 1993; 94: 105-110.

36. Gosset P, Tsicopoulos A, Wallaert B, Joseph M, Capron A, Tonnel A. Tumor necrosis factor- $\alpha$ and interleukin6 production by human mononuclear phagocytes from allergic asthmatics after IgE-dependent stimulation. Am Rev Respir Dis 1992; 146: 768-774.

37. Reynolds HY. Bronchoalveolar lavage. Am Rev Respir Dis 1987; 135: 250-263. 